\title{
SPL Pharmacokinetic Effect Consequences Terminology
}

National Cancer Institute

\section{Source}

National Cancer Institute. SPL Pharmacokinetic Effect Consequences Terminology. NCI

Thesaurus. Code C54600.

Terminology used for representation of information on consequences resulted from pharmacokinetic interactions between the drug and another drug or food in the framework of the Structured Product Labeling documentation. 